УДК 341.64

DOI https://doi.org/10.32849/2663-5313/2020.6.45

Константин Искров,

канд. юрид. наук, адвокат

\title{
ПРИМЕНЕНИЕ СТАТЬИ 87 КОНВЕНЦИИ ООН ПО МОРСКОМУ ПРАВУ В ДЕЛЕ СУДНА NORSTAR
}

Правовой режим использования открытого моря как одной из частей мирового океана, на первыци взгляд, является самым простым согласно правилам, предусмотренным в статьях Конвениии ООН по морскому праву. Однако, как показывает судебная практика применения статей Конвениии, среди государств существует разное понимание правил использования открытого моря и обязанностей стран в их соблюдении. Это возможно является следствием того, что открытость перечня видов деятельности, обозначенных в статье 87 Конвенции, приводит к появлению новых интересов у государств в использовании открытого моря, и такие интересы вступают в конкуренцию с целями иньх государств, наиболее экономически и географически приближенных к этой части мирового океана.

В представленной статье будет рассмотрен случай возможности нарушения статьи 87 Конвениии в связи с арестом судна, находившегося во внутренних водах государства, за деятельность по бункеровке, осуществленную в открытом море.

Деятельность по бункеровки судов в тех частях моря, правовой режим которьх допускает выполнение их беспошлинно, является обычной для многих бункеровщиков и потребителей бункера и масел. Спор, который рассмотрен в рамках статьи, показывает отношение Трибунала к праву бункеровки как деятельности, осуществляемой в пределах свободы судоходства, а не иного вида деятельности в открытом море и возможности прибрежного государства пресекать/вмешиваться в такую деятельность судна, если она влияет на его фискальные правила. В данном деле Трибунал оставил без внимания позииию государства-ответчика в оценке правомерности операции по бункеровке, при которой судно выходило за предель территориального моря с иелью выполнения беспошлинной бункеровки и возвращалось в территориальные воды прибрежного государства, где потребляло его. Считаем, что отказ Трибунала рассматривать подобную операцию с применением статей Конвенщии выходит за предель её положений, однако это должно регулироваться нормами других международных договоров и внутренним правом прибрежного государства.

Данный спор в части соблюдения статьи 87 Конвениии возник между государствами Панама и Италия в деле судна NORSTAR, рассмотрение которого продолжит серию наших публикаций по изучению судебной практики Международного трибунала ООН по морскому праву.

Ключевые слова: открытое море, международный трибунал ООН по морскому праву, арест судов.

Постановка проблемы. Данная публикация является продолжением рассмотрения судебной практики Международного Трибунала ООН по морскому праву (далее по тексту - Трибунал), которая начата нами в предыдущих статьях

Статья состоит из анализа материала, изученного по судебному делу судна NORSTAR. Дело инициировано Панамой против Италии. Решение по делу Трибунал принял 10.04.2019 года. Хотелось бы отметить, что, исходя из количества дел, рассмотренных или находящихся на рассмотрении Трибунала, Панама является одним из самых активных государств в своей практике защиты интересов в данной международной юстиции. Это, возможно, говорит о том, что Панама, как страна так называемого «удобного флага», пересматривает свою государственную политику для усиления защиты доходного для неё экономического направления - регистрации судов, становясь более привлекательной для собственников флота в защите их интересов, в том числе государством флага в Трибунале.

Цель статьи - изучение практики применения статей Конвенции ООН по морскому праву 1982 года (далее по тексту Конвенция).

Изложение основного материала. Перейдем непосредственно к спору в деле судна NORSTAR. Основой для его начала стало задержание и арест указанного судна в 1998 году в порту Испании по ходатайству Италии, направленному властям Испании на основании Конвенции о взаимной помощи в уголовных делах от 20.04.1959 г. Судно NORSTAR было арестовано в рамках уголовного дела об уклонении от уплаты налогов, 
расследуемого полицией Италии. Согласно доказательствам полиции, судно использовалось для бункеровки других судов за пределами территориального моря Италии, после чего забункерованные суда возвращались во внутренние воды Италии и другие государства Европейского Союза.

Принимая решение, Трибунал досконально рассмотрел содержание деятельности, в которой использовалось судно NORSTAR, с целью определения правомерности его задержания и ареста по решению властей Италии. В данной публикации мы не будем углубляться в анализ сути внутреннего расследования Италии, которое стало основанием для применения таких мер к судну, мы лишь сосредоточимся на оценке Трибунала в применении статей Конвенции в данном деле.

Начнем с некоторых процедурных вопросов рассмотрения дела, на которых настаивали стороны и по которым Трибунал сделал свои выводы. Данные выводы как прецедентные правила судебного процесса будут в дальнейшем использоваться другими государствами как сторонами в спорах, тем они и ценны.

Показания свидетелей. По заявлению Италии показания свидетелей, которые имеют финансовый интерес к делу, не имеют ценности, при этом Италия высказала следующий тезис: «доказательства свидетелей, заинтересованных в деле и особенно имеющих финансовый интерес, имеют меньшую ценность, чем доказательства тех, кто не имеет такого интереса». Трибунал ответил на это таким образом: «ценность каждого показания будет браться во внимание inter alia, относятся ли показания к существующим фактам или представляют собой персональное мнение, являются ли они знаниями из «первых рук», как они будут протестированы через перекрестный допрос, как они будут соотноситься с другими доказательствами [2, с. 15]. По нашему мнению, разумный и обоснованный ответ Трибунала, который даже может браться в пример для оценки показаний свидетелей во внутренних судебных процессах.

Еще один процедурный момент рассмотрения дела, который заслуживает внимания. На стадии предварительного возражения (Preliminary Objection), где одним из основных вопросов является определение допустимости юрисдикции Трибунала в споре между государствами, принимается отдельное решение (Judgment of Preliminary Objection), в котором, кроме вопроса юрисдикции, может быть решен вопрос освобождения судна из-под ареста против предо- ставления определенной Трибуналом суммы денежной гарантии или иного финансового обеспечения. На данной стадии Трибунал определяет, точнее сказать, обосновано предполагает, произошло ли нарушение положений Конвенции государством-«ответчиком», и указывает на статьи Конвенции, которые предположительно были нарушены. Это очень важное процедурное решение Трибунала, поскольку на стадии по существу дела государство-«истец» будет доказывать только их нарушение, в свою очередь государство-«ответчик» - опровергать. Таким образом, определяются пределы требований на данной стадии, которые уже по существу не подлежат расширению. В деле судна NORSTAR Панама, предварительно заявив о нарушении статей 87, 300 Конвенции, в заявлении по существу указала на иные статьи, ссылаясь на то, что новые статьи уместны и соотносятся с ранее заявленными. В свою очередь Италия, руководствуясь правилом пределов требований, обозначенных в решении на стадии предварительного возражения, указала, что такое дополнение означает фактически заявление нового иска, при этом опираясь на позицию Трибунала в другом деле - относительно судна LOUISA, согласно которой последующие заявления должны быть оценены на условиях, ранее заявленных. Требования не должны выходить за пределы основного заявления. Спор, поданный на рассмотрение Трибунала, не должен трансформироваться в другой спор, иной по характеру. Заявление новых требований возможно, если они прямо вытекают из заявленных или скрыты в них [2, c. 18].

Трибунал по делу судна NORSTAR признал своё право обратиться к другим статьям Конвенции, которые были также возможно нарушены Италией и не заявлены Панамой на стадии предварительного возражения и не определены в решении Трибунала как допустимые в данном споре. При этом Трибунал руководствовался статьей 293 Конвенции, в которой дается право Трибуналу применять другие положения настоящей Конвенции или иные нормы международного права, а также объяснил, что если будет рассматриваться нарушение правил открытого моря по статье 87, то положения статьи 92 об юрисдикции государства флага в открытом море, ранее не заявленной Панамой, будут уместными и находятся в связи с статьей 87 Конвенции.

Далее мы перейдем к выводам Трибунала, сформулированным в решении по сути нарушения Италией статьи 87 Конвенции, которая имеет следующее содержание: 
Статья 87 «СВБОДА ОТКРЫТОГО MOРЯ»

1. Открытое море открыто для всех государств, как прибрежных, так и не имеющих выхода к морю. Свобода открытого моря осуществляется в соответствии с условиями, определяемыми в настоящей Конвенции, и другими нормами международного права. Она включает, в частности, как для прибрежных государств, так и для государств, не имеющих выхода к морю: а) свободу судоходства; b) свободу полетов; с) свободу прокладывать подводные кабели и трубопроводы, с соблюдением Части VI; d) свободу возводить искусственные острова и другие установки, допускаемые в соответствии с международным правом, с соблюдением Части VI; е) свободу рыболовства, с соблюдением условий, изложенных в Разделе 2; f) свободу научных исследований, с соблюдением частей VI и XIII.

2. Все государства осуществляют эти свободы, должным образом учитывая заинтересованность других государств в пользовании свободой открытого моря, а также должным образом учитывая права, предусмотренные настоящей Конвенцией в отношении деятельности в Районе».

Характеризуя свободу открытого моря, будет уместным сослаться на следующие объяснения данного права.

Концепция свободы плавания в открытом море была объектом ряда международных арбитражей и судебных решений. К примеру, в решении постоянно действующего Международного Суда от 02.12.1921 г. в деле между Великобританией и Соединенными Штатами было подтверждено: «только исключительно в специальной Конвенции или во время войны вмешательство крейсера в плавание иностранного судна, выполняющего законный рейс в открытом море, является обоснованным и законным» [3, с. 58].

Свобода судоходства включает все права, связанные с ней или содержащиеся в самой этой свободе. Вследствие этого в открытом море предполагается, что правила свободы применяются не только к действиям, упомянутым в статье 87, но также к новой или не названной деятельности, которая предполагает законное использование открытого моря [4, с. 4].

В принципе, деятельность, которая совместима со статусом открытого моря и которая не предусматривает никаких претензий на присвоение прав другого государства или международного морского дна, должна допускаться, если это не запрещено каким-либо конкретным правилом Конвенции [5, с. 243].

Судья Вукас в своем отдельном мнении по делу судна SAIGA подтвердил, что бунке- ровку, которая была довольно новым видом деятельности в то время, когда она не была прямо упомянута на Конференции, следует рассматривать в качестве международного законного использования моря [6, с. 17].

В настоящее время бункеровка является законной деятельностью и рассматривается в свободе судоходства.

Казалось бы, что сложного и противоречивого в таком простом принципе, как свобода открытого моря. Оказывается, как показывает практика, открытость перечня видов деятельности, обозначенных в статье 87 , будет приводить к появлению новых интересов в части использования открытого моря, которые будут вступать в конкуренцию с интересами других государств, наиболее географически приближенных к этой части открытого моря, и, как следствие, появлению противоречий и споров. Это первое. Второе, встречаются разные трактовки свободы судоходства в открытом море, что также проявилось в деле NORSTAR.

Бункеровка как деятельность в открытом море стала сутью спора между Панамой и Италией в деле судна NORSTAR. Панама настаивала, что было вмешательство в данную деятельность со стороны Италии. В свою очередь Италия, возражая, указывала на то, что сама бункеровка не являлась основанием для ареста, основанием же являлось уклонение от уплаты налогов в деятельности с использованием судна NORSTAR.

Панама настаивала на том, что есть нарушение свободы судоходства в открытом море, предусмотренной статьей 87 Конвенции, которая, по её мнению, означает возможность покинуть порт и получить доступ к открытому морю в любое время. На данное утверждение Италия отреагировала следующим образом: «в таком случае с позиции Панамы последствия неправомерного ареста Италии были бы одинаковы, независимо от того, где был совершен арест, потому что это в любом случае ограничило бы свободу судна NORSTAR для плавания или плавания в открытом море». Панама использует слово «абсолют» для описания свободы судоходства в порту и приходит к выводу, что морское право четко определяет, что судно имеет право на свободу судоходства в любое время и везде, даже когда оно пришвартовано [2, c. 35-37].

К тому, как Трибунал разрешил такое толкование свободы судоходства в открытом море, вернемся позже в данной статье.

Следующее, что, на наш взгляд, является важным, это обстоятельства задержания и ареста судна NORSTAR по решению властей Италии. Как упоминали выше, 
судно было задержано и арестовано в порту Испании по ходатайству Италии, то есть во внутренних водах государства, однако за деятельность, которую судно осуществляло в открытом море. Трибуналу необходимо было разобраться в данных обстоятельствах и определить, нарушена ли статья $87 \mathrm{KoH}-$ венции. Панама утверждала, что бункеровка в открытом море включается в свободу судоходства (fall within the freedom of navigation). Против данного утверждения Италия не возражала, и с этим согласился Трибунал. Следует отметить, что бункеровка - это не новый вид деятельности государства в открытом море по открытому перечню свобод согласно части 1 статьи 87 Конвенции, а деятельность, включенная в право свободы судоходства.

Открытое море - это часть мирового океана, на которую не распространяется суверенитет и, как следствие, юрисдикция ни одного из государств, кроме как государства флага судна. Считается ли арест судна, причалившего в пору, нарушением свободы судоходства (freedom of navigation) в открытом море? Согласно мнению Италии, это невозможно по следующим причинам. Вмешательство государства в плавание иностранного судна в открытом море происходит посредством принудительных действий или какого-либо другого вида физического вмешательства в движения судна. Ещё в 1921 году постоянно действующий Международный суд в деле Wanderer между Великобританией и Соединенными Штатами определил: «фундаментальный принцип международного морского права в том, что ни одна нация не может осуществить право посещения и обыска иностранных судов, преследующих законное плавание в открытом море, кроме как во время войны или по специальному соглашению» [2, с. 47].

Кроме того, прецедентное право Трибунала показывает, что в случае нарушения части 1 статьи 87 Конвенции факты, как правило, связаны с поведением, которое влечет за собой физическое вмешательство в судоходство иностранного судна.

В деле судна ARTIC SUNRISE нарушение статьи 87 заключалось в остановке, расследовании, инспекции, задержании и аресте судна ARTIC SUNRISE. В деле судна SAIGA обжалованное поведение состояло, inter alia, в атаке судна SAIGA и его экипажа в исключительной экономической зоне СьерраЛеоне, последующем задержании и аресте, выгрузке груза [2, с. 44].

То есть позиция Италии строилась на том, что допустимо рассматривать нарушение права свободы судоходства, включающего в себя бункеровку, только в случае принудительных, в том числе физических, действий (enforcement) государства по отношению к иностранному судну в открытом море. Арест судна NORSTAR произошел в порту Испании, судно стояло причаленное к причальной стенке на протяжении более трех месяцев до самого ареста.

Панама, в свою очередь, такое поведение Италии предлагала рассмотреть с другой точки зрения. Может ли государство распространять свою юрисдикцию и давать оценку деятельности судна, которое в момент осуществления такой деятельности находится вне его юрисдикции? Италия нарушает принцип экстерриториальности, присущий открытому морю [2, с. 48].

Для того чтобы разобраться в данном вопросе, Трибунал изучил все документы Италии, на основании которых был произведен арест во внутренних водах Испании, при этом Италия настаивала на том, что деятельность, которая была криминализирована, не касалась бункеровки в открытом море, а содержала состав преступления - уклонения от уплаты налогов, совершенного на территории Италии.

Кроме того, Италия в ходе судебных слушаний согласилась с тем, что так называемый «chilling effect» (эффект охлаждения) может составлять часть принудительных действий (short part of enforcement action) и считаться нарушением статьи 87 Конвенции. В этом отношении Италия в качестве примера указала: «это происходит, когда часть законодательства, позволяющая осуществлять экстерриториальную судебную юрисдикцию, в описании и, следовательно, криминализации определенного поведения в открытом море. Например, для того чтобы исключить поведение судна, которое сдерживает себя от пересечения тех участков моря, где применимо экстерриториальное законодательство, может иметь отношение к нарушению статьи 87 Конвенции. При этом Италия указала, что её решение об аресте, как обеспечительная мера в уголовном деле, не является обнародованным и общеизвестным документом. Кроме того, согласно внутреннему праву оно предусматривает свою процедуру секретного принятия и внезапного осуществления с целью выполнения задач уголовного расследования, поэтому в решении Италии об apecте отсутствует так называемый «chilling effect» [2, c. 54].

В отношении осуществления экстерриториальной юрисдикции Италия утверждает, что расширение экстерриториальной юрисдикции может быть запрещено в соответствии с другими положениями Конвенции, например статьи 89, но не с точки зрения 
положений статьи 87, о нарушении которой заявлено. По мнению Италии, даже если предположить, что она расширила сферу своей юрисдикции в решении об аресте экстерриториально, без конкретного вмешательства в свободу судоходства такое поведение не будет нарушать статью 87 Конвенции [2, c. 38]

По нашему мнению, Трибунал в своём решении по делу судна NORSTAR сделал более глубокий вывод о том, что представляет собой нарушение принципа свободы судоходства. Трибунал определил, что свобода судоходства - это право, которое находится вне суверенитетов и юрисдикций, - это первично; должно ли и может ли оно быть нарушено только в случае осуществление принудительных (физических) действий государства против иностранного судна в открытом море - это вторично. Оценивая решение властей Италии об аресте судна NORSTAR, Трибунал пришел к выводу, что было нарушение свободы судоходства, закрепленной в статье 87 Конвенции.

По мнению Трибунала, не имеет значения, был или нет осуществлен «chilling effect» в документах Италии, предоставляющий право этому государству распространить свою юрисдикцию на деятельность судна в открытом море. Независимо от этого эффекта любое действие, которое предусматривает своим предметом деятельность иностранного судна в открытом море под юрисдикцией государства, не являющегося государством флага судна, составляет нарушение свободы судоходства, за исключением исключительных случаев, прямо предусмотренных в Конвенции и других международных договорах. Принцип исключительной юрисдикции государства флага является неотъемлемым компонентом свободы навигации в соответствии со статьей $87 \mathrm{KoH}^{-}$ венции. Этот принцип запрещает не только осуществление принудительной юрисдикции в открытом море государства иного, чем государство флага, но также распространяется на его предписывающую юрисдикцию, на законную деятельность, выполняемую иностранными судами в открытом море. Поэтому Трибунал не смог принять доводы Италии о том, что статья 87 не касается территориальности или экстерриториальности, а скорее является помехой в навигации и что экстерриториальность не является тестом в оценке нарушения статьи 87. Если государство применяет свой уголовный или таможенный закон к открытому морю и криминализирует деятельность, выполняемую иностранным судном в этой связи, это будет представлять собой нарушение статьи 87
Конвенции, если это не оправдано самой Конвенцией или другими международными договорами. Это было бы так, даже если государство воздерживалось бы от принудительного исполнения этих законов в открытом море [2, с. 58$]$

Деятельность судна NORSTAR была разложена Трибуналом по сути на следующие элементы:

- дизельное топливо и масла были куплены освобожденными от налогов в итальянском порту и загружены на судно NORSTAR;

- судно NORSTAR бункеровало мегаяхты за пределами территориального моря Италии;

- мега-яхты возвращались в итальянский порт или другие порты стран Европейского Союза, не декларируя наличие дизельного топлива/масла.

Трибунал установил, что хотя первый и третий элементы могли иметь место на территории Италии, второй элемент произошел за пределами территориального моря Италии, то есть в открытом море.

Ранее мы упоминали о ещё одном заявлении Панамы, связанном с нарушением свободы судоходства, которое ею было представлено как право не только пересекать открытое море, но и иметь к нему постоянный доступ.

По данному требованию об определении места выполнения свободы судоходства Трибунал сделал следующий вывод. Конвенция предусматривает сложный режим навигации. Навигационные права, которыми пользуются иностранные суда, различаются в различных морских зонах. Свобода судоходства распространяется как на открытое море, так и на исключительную экономическую зону в соответствии с частью 1 статьи 58 Конвенции.

Трибунал отмечает, что государство осуществляет суверенитет в своих внутренних водах. Иностранные суда не имеют права плавания, если это не предусмотрено Конвенцией или другими нормами международного права. Поэтому стремление интерпретировать свободу навигации как охватывающую право покидать порт и получить доступ к открытому морю несовместимо с правовым режимом внутренних вод. Требования Панамы в этой части не применимы к статье 87 Конвенции [2, с. 34].

Хотелось бы остановиться на других моментах рассмотренного дела, которые хотя и не составляли ключевое бремя доказывания каждой из сторон, однако являются ценными с точки зрения правильного применения положений Конвенции. 
Например, в своем заявлении Панама утверждала, что Италия также нарушила часть 2 статьи 87 Конвенции, которая предусматривает, что все государства осуществляют эти свободы (предусмотренные частью 1 статьи 87), должным образом учитывая заинтересованность других государств в пользовании свободой открытого моря, а также должным образом учитывая права, предусмотренные настоящей Конвенцией в отношении деятельности в Районе.

Панама настаивала на том, что стандарт «должным образом» (due regard) требует от всех государств, осуществляя свои свободы в открытом море, учитывать интересы других государств и воздерживаться от действий, препятствующих осуществлению другими государствами параллельно своих свобод в открытом море.

В отношении части 2 статьи 87 Конвенции Италия заявила, что обязательство должным образом учитывать права других государств, в соответствии с данными положениями, возлагается именно на государства, которые осуществляют данные свободы, предусмотренные частью 1 статьи 87 Конвенции Поэтому Панама, а не Италия, ссылалась на свободу судоходства по части 1 статьи 87 , и должна выполнять данное право согласно части 2 статьи 87 Конвенции.

Трибунал поддержал позицию Италии в правильном понимании связи части 1 и части 2 статьи 87 Конвенции.

В одном из своих документов Италия обосновывала возможность ареста судна NORSTAR, руководствуясь доктриной конструктивного присутствия и преследования по горячим следам (constructive presence doctrine and hot pursuit). Доктрина конструктивного присутствия позволяет прибрежному государству применять свою юрисдикцию над иностранными судами, действующими совместно с другим судном (контактное судно), или самолетами, нарушившими законы прибрежного государства в водах, над которыми прибрежное государство может осуществлять юрисдикцию. Для того чтобы осуществлять юрисдикцию над «материнским судном», «контактное судно» должно физически присутствовать в водах прибрежного государства или быть предметом юрисдикции прибрежного государства согласно доктрине преследования по горячим следам. После того, как преследование «материнского судна» началось, оно может продолжаться до тех пор, пока оно не перестанет быть непрерывным или пока «материнское судно» не войдет в территориальные воды другого государства.

Панама утверждала, что данная доктрина в документах по аресту судна NORSTAR была представлена так, что судно NORSTAR «материнское судно», а мега-яхты, которые были ею забункерованы, - «контактные суда», которые после бункеровки возвращались в территориальное море Италии, тем самым вступили в контакт с юрисдикцией прибрежного государства и были предметом преследования по горячим следам. По мнению Панамы, использование данной доктрины Италией само по себе показывает, что судно NORSTAR не было арестовано за деятельность в территориальных водах Италии [2, c. 18].

Италия опровергала данный аргумент тем, что выполнение данной доктрины предполагает осуществление ареста судна именно в открытом море, чего никогда не было, судно было арестовано во внутренних водах Испании. Трибунал согласился с мнением Италии.

Следующий аргумент Панамы не нашел своего отражения в решении Трибунала, однако, по нашему мнению, в целях изучения практики применения Конвенции заслуживает внимания. Статья 3 проекта статей об ответственности государств за международно-противоправное деяние определяет, что квалификация деяния государства как международно-противоправного определяется международным правом. На такую квалификацию не влияет квалификация этого деяния как правомерного по внутреннему праву. Панама, трактуя данную норму, указывает, что государству не разрешено использовать суверенное право как основание для оправдания ареста судна за действия, имеющие место за пределами юрисдикции такого государства.

В деле S.S. «Wimbledon» постоянно действующий Международный Суд отклонил аргументы Германии о том, что прохождение судна через Кельнский канал составляет нарушение приказов о нейтралитете Германии. В этом деле приказы о нейтралитете не могли превалировать над соглашением о мире, по которому Германия обязана разрешать прохождения судна через Кельнский канал. Международный суд указал: «это общий принцип международного права, что над отношениями, которые регулируются между сторонами договором, не могут превалировать нормы муниципального права» [7, c. 15].

Панама, ссылаясь на данный прецедент и на проект статей об ответственности государств, указала, что если она с Италией является участницей Конвенции по морскому праву, то договоренности по договору не могут быть нарушены применением внутреннего права. 
Данный аргумент Панамы не нашел своего ответа в возражениях Италии и объяснения в решении Трибунала.

\section{Выводы}

Считаем, что данная статья будет являться продолжением серии публикаций по правоприменительной практике Трибунала, основанной на положениях Конвенции ООН по морскому праву 1982 года, правильность применения которой имеет важное значение для Украины.

\section{Список использованных источников:}

1. Конвенция Организации Объединенных Наций по морскому праву / Верховна Рада України. URL: http://zakon.rada.gov.ua/laws/ show/162/95-вр (дата звернення: 05.05.2020).
2. List of Cases. International Tribunal for the Law of the Sea. URL: http://www.itlos.org/cases/ list-of-cases (дата звернення: 05.05.2020).

3. Owners of the Jessia, the Thomas F. Bayard and the Pescawha (Great Britain) v. United States, 2 December 1921, Reports of International Arbitral Awards, Vol. VI. P. 58

4. Tulllio Treves, «High Seas», in Max Planck Encyclopedia of Public International Law (Oxford University Press). P. 4;

5. David Attard and Partricia Mallia, «The High Seas» in The IMLI Manual on International Maritime Law: Volume 1: The Law of the Law (eds Attard and other) (Oxford University Press 2014) P. 243.

6. The M/V Saiga (No 2) Case, Saint Vincent and the Grenadines v. Guinea, 1 July 1999, Separate Opinion Judge Vukas. P. 17.

7. S.S. Wimbiedon, 1923, P.C.I.J. Series A. No 1. P. 15.

Kostiantyn Iskrov. Use in practice Article 87 of the UN Convention on the Law of the Sea in case of the $\mathrm{m} / \mathrm{v}$ NORSTAR

The legal regime for the use of the open seas, as one of the parts of the world oceans, from first glance, is the simplest according to the rules provided in articles of the UN Convention on the Law of the Sea. However, as showes the judicial practice of applying the articles of the Convention, among states there is a different understanding of the rules for the use of the open seas and their responsibilities in complying with these rules. This is probably possibly due to the fact that the open list of activities specified in Article 87 of the Convention will lead to the emergence of new interests among states for use of the open seas, and such interests will compete with the aims of other states that are most economically and geographically close to this part of the open seas.

In the present article, examined the incident of violation of article 87 of the Convention in connection with arrest of the vessel located in the inland waters of the state in the moment of arrest for activities of bunkering carried out in the open seas.

Commercial activities for bunkering vessels in parts of the sea where legal regime permits them to be free from customs tax is common for many bunkers and consumers of bunkers and oils. The dispute, which is considered within the article, shows the attitude of the Tribunal to the right of bunkering as an activity carried out within the freedom of navigation, ant is isn't another type of activity on the open seas and the ability of a coastal state to suppress / interfere to such ship activity if it affects its fiscal rules. In this case, the Tribunal disregarded the position of the respondent State on the assessment of the legality of the bunkering operation, in which the vessel went beyond the territorial sea in order to perform free bunkering and returned to the territorial waters of the coastal state where consumed it. We believe that the refusal of the Tribunal to consider such an operation with using the articles of the Convention not comply with its provisions, and should be governed by the norms of other international treaties and the domestic law of the coastal state.

This dispute regarding compliance of article 87 of the Convention arose between states of Panama and Italy in the case of the $m / v$ NORSTAR, the consideration of which will continue our series of publications about court practice of the UN International Tribunal for the Law of the Sea.

Key words: high seas, the UN International Tribunal of the Law of the Sea, arrest of the vessel. 